\title{
Do self-perceived opinion leaders actually lead opinions? Evidence from an observational study on political conversations
}

Geber, Sarah

\begin{abstract}
Opinion leadership is one of the most prominent concepts in communication sciences. A popular method for studying opinion leadership is the use of self-designating scales. The present study examines whether opinion leaders who are identified by self-designating scales literally lead opinions, that is, actually influence others. For this purpose, 78 dyads of friends were interviewed, and their political conversations were observed. The results reveal that self-perceived opinion leadership is associated with aspects of the influence process (i.e., goal to influence, influential communication, and opinion effects) and with other-perceptions of opinion leadership in political conversations. However, given the small effects and the significant role of the interaction partner with regard to the influence process, it is concluded that the extent to which self-designating scales are able to represent the complexity of social reality is limited.
\end{abstract}

DOI: https://doi.org/10.1080/08824096.2019.1598856

Posted at the Zurich Open Repository and Archive, University of Zurich

ZORA URL: https://doi.org/10.5167/uzh-175856

Journal Article

Accepted Version

Originally published at:

Geber, Sarah (2019). Do self-perceived opinion leaders actually lead opinions? Evidence from an observational study on political conversations. Communication Research Reports, 36(3):209-219.

DOI: https://doi.org/10.1080/08824096.2019.1598856 
Do Self-Perceived Opinion Leaders Actually Lead Opinions? Evidence From an Observational Study on Political Conversations

\author{
Sarah Geber
}

This is a post-print version. The publisher's version is available at:

https://tandfonline.com/doi/full/10.1080/08824096.2019.1598856

Please cite as:

Geber, S. (2019). Do self-perceived opinion leaders actually lead opinions? Evidence from an observational study on political conversations. Communication Research Reports, 3, 1-11. doi:10.1080/08824096.2019.1598856 


\begin{abstract}
Opinion leadership is one of the most prominent concepts in communication sciences. A popular method for studying opinion leadership is the use of self-designating scales. The present study examines whether opinion leaders who are identified by self-designating scales literally lead opinions, that is, actually influence others. For this purpose, 78 dyads of friends were interviewed and their political conversations were observed. The results reveal that selfperceived opinion leadership is associated with aspects of the influence process (i.e., goal to influence, influential communication, and opinion effects) and with other-perceptions of opinion leadership in political conversations. However, given the small effects and the significant role of the interaction partner with regard to the influence process, it is concluded that the extent to which self-designating scales are able to represent the complexity of social reality is limited.
\end{abstract}

Keywords: opinion leadership, self-designating scales, observational study, dyadic analysis, partner effects 
Opinion leadership is one of the most prominent concepts in communication sciences (Katz \& Fialkoff, 2017). Opinion leaders are persons who literally lead opinions, meaning that they exert "influence on the opinion of others" (Hellevik \& Bjørklund, 1991, p. 158). Because of their influence potential, "thousands of studies" (Weimann, 1994, p. 88) have examined opinion leaders in diverse thematic contexts, such as politics (e.g., Lazarsfeld, Berelson, \& Gaudet, 1944), health communication (e.g., Rice, Wu, Li, Detels, \& RotheramBorus, 2012), or fashion (e.g., Summers, 1970).

Various measurement approaches have been used to identify opinion leaders (for a review, see Rogers \& Cartano, 1962; Valente \& Pumpuang, 2006). Comparable to the measurement of other communication traits, such as communication competence (McCroskey \& McCroskey, 1988), the most prominent method for assessing opinion leadership is the use of self-designating scales as they can be easily administered in surveys (Valente \& Pumpuang, 2006). Self-designating opinion leadership scales ask a series of questions to determine the degree to which respondents perceive themselves to be influential (Weimann, 1994, p. 35). However, as for self-designating scales of communication behavior in general (Baumeister, Vohs, \& Funder, 2007), the validity of self-designating opinion leadership scales can be questioned (Weimann, 1994, p. 37). The current study focuses on political opinion leadership and asks whether self-perceived political opinion leaders actually influence others.

Merton's (1968) notion that influence is "not an abstract attribute of a person" but "a process implicating two or more people" (p. 464) points to the limitations of the validity of self-designating opinion leadership scales in two ways. First, Merton's (1968) definition indicate the importance of the context whereas self-designating scales measure opinion leadership independently of interaction partners and situations. In social science literature, the issue of context has been addressed in trait-vs-state (e.g., Steyer, Schmitt, \& Eid, 1999), person-by-situation (e.g., Zuroff, 1982), and dispositional-vs-situational debates (e.g., 
Solomon, 1978). Thus, self-designating opinion leadership scales measure the disposition, the general tendency to act as an opinion leader, but they ignore whether opinion leadership has implications in concrete situations, whether opinion leaders actually influence others (see also Baumeister et al., 2007). The situations in which political opinion leadership takes place can be specified as everyday political conversations (Lazarsfeld et al., 1944). According to opinion leadership definitions, in such political conversations, opinion leaders aim to influence the conversation partner's opinion (Flynn, Goldsmith, \& Eastman, 1996; Lazarsfeld et al., 1944), use influential communication (Flynn, Goldsmith \& Eastman, 1994; Turcotte et al., 2015), and affect the partner's opinion (Hellevik \& Bjørklund, 1991; Rogers, 1995). Consequently, self-designating scales will be a valid way to identify opinion leaders if they are reflected in these aspects of influence in political conversations. Therefore, this research report asks the question of whether self-perceived opinion leadership corresponds with a) the influence goal, $b$ ) influential communication, and c) opinion effects (RQ1).

Second, the identification of opinion leadership by self-assessment measures selfperceived opinion leadership - to score high on the scale, respondents have to see themselves as influential (Weimann, 1994, p. 37). However, Merton's (1968) notion that influence is a two-sided process points to the importance of the interactional partners' perceptions. The issue of self- and other-perception has been extensively addressed in social sciences, for example, in the social relations model (Kenny \& La Voie, 1984). In the case of opinion leadership, it has been asserted that opinion leaders' self-perception is not a sufficient precondition to define them, as they heavily depend on the "social recognition" (Weimann, 1994, p. 83) of their followers. Therefore, self-designating scales will be a valid measurement approach to opinion leadership if they are reflected in the conversation partners' perceptions. The present research report asks whether self-perceived opinion leadership corresponds with other-perceived opinion leadership in political conversations (RQ2). 


\section{Method}

\section{Procedures}

To answer both questions, 82 dyads of friends or acquaintances were recruited through an article in the regional press and compensated with 30 Euro. In a first step, both dyadic partners answered (independently of each other) questions on self-perceived opinion leadership amongst others. Two weeks later, the dyad partners were invited to attend a lab where they talked for ten minutes in absence of researchers about a short clipping from a political talk show on immigration policy. Immigration policy is considered an appropriate conversation topic because it equally affects everyday life of all populations groups (in contrast to pension policy, for example). The conversations were audio recorded and transcribed subsequently. Immediately after the political conversations, the dyad partners were moved to separate rooms and interviewed on their conversation goals and on their perceptions (i.e., opinion effects; perceived opinion leadership) via a paper-and-pencil questionnaire.

\section{Sample}

After data cleansing,${ }^{1}$ the final sample comprised 78 dyads of friends or acquaintances, respectively, 156 individuals. The participants' age ranged from 18 to 79 years $(M=34.40$, $S D=13.27)$, with slightly more women $(58 \%)$. Nearly half of the participants had at least graduated from college (46\%) indicating that the sample's education was above-average. The participants had been acquainted for almost 8 years on average $(M=7.79, S D=8.25)$.

\section{Measurements}

(Self-perceived) opinion leadership. Based on the first opinion leadership scales of Lazarsfeld et al. (1944) and Katz and Lazarsfeld (1955), different self-designating scales have survey.

\footnotetext{
${ }^{1}$ Four dyads were excluded due to inconsistencies in socio demographics between the first and second
} 
been developed (e.g., Flynn et al., 1996; Rogers \& Cartano, 1962). The present study used a modified version of Childers" (1986) scale as it is "the most popular in practice" (Gnambs \& Batinic, 2011, p. 95). The scale's items were applied to politics ${ }^{2}$ and-as it also has been done in current research to streamline questionnaire administration (e.g., Mangold \& Bachl, 2018) - the items were translated to statements with five-point response options ranging from $1=$ does not apply at all to $5=$ does fully apply instead of using item-specific response formats (e.g., $5=$ very often to $1=$ never $; 5=$ told a number of people to $1=$ told no one). Agreement with the items was measured in the online survey two weeks before the conversation. For the sake of unidimensionality, the item on generic leadership ${ }^{3}$ was excluded (see also Flynn, Goldsmith, \& Eastman, 1994). The 5-item scale indicated high internal reliability (Cronbach's $\alpha=.91$; Nunnally, 1978).

Table 1

Opinion Leadership

$M \quad S D$

(1) I often talk to my friends and acquaintances about politics.

$3.36 \quad 1.19$

(2) When I talk with my friends and acquaintances about politics, I give a great deal of information.

(3) During the past six months, I have informed many of my friends and acquaintances about politics.

(4) Compared to my friends, I am likely to be asked about politics.

(5) In discussions of politics, I most often tell my friends about politics.

2 The original scale of Childers (1986) measures opinion leadership regarding cable television.

${ }^{3}$ Generic leadership item: "Overall, I am often used as a source of advice by my friends and acquaintances." 
Note. $N=156 ; 5$-point scale: $1=$ does not apply at all to $5=$ does fully apply.

Influence goal. The goal to influence opinions is at the core of the opinion leadership concept (Flynn et al., 1996). The first opinion leadership scale of Lazarsfeld et al. (1944) identified opinion leaders by asking if they „have [...] tried to convince anyone of [their] political ideas recently" (p. 50). Accordingly, the influence goal was measured by two items on the five-point agreement scale (see above) in the questionnaire immediately after the conversation: (1) "It was important to me to convince my conversation partner of my opinion."; (2) "It was important to me to win my conversation partner for my opinion." The Spearman-Brown coefficient ${ }^{4}$ indicates reliability (Spearman-Brown $\rho=.76$ ), thus, an average index was built $(M=2.29, S D=1.03)$.

Argument-based opinion giving. Opinion leaders give opinions (Troldahl \& van Dam, 1965) and should be able to provide arguments for their claims given their expertise (Gnambs \& Batinic, 2012). Persuasion studies reveal that messages with explicit claims and arguments are influential (O'Keefe, 1997, 1998). Consequently, argument-based opinion giving was measured via a content analysis of the conversation transcripts, conducted by three coders. Argument-based opinion giving is a combined measure, composed of an opinion expression and a further statement providing elaboration. Units for coding were identified at the level of the turn, that is, a speaker's utterance without interruption by the conversation partner ${ }^{5}$. Following Stromer-Galley (2007), every expression including a judgement was coded as an opinion (p. 10). This definition comprises explicit opinion expressions like general judgements as well as implicitly stated opinions in form of praise, critique, and calls to action. Elaborations on the issue could appear in statements providing a definition, an example, a solution for a problem, a consequence of a problem, a sign that something exists or

\footnotetext{
${ }^{4}$ The Spearman-Brown coefficient is the most adequate reliability coefficient for two-item scales (Eisinga, Grotenhuis, \& Pelzer, 2013).

${ }^{5}$ To determine the identification reliability, three conversations were randomly selected, for which the coders identified the coding units. An agreement in 97 percent of the cases was achieved.
} 
does not exist (see also Stromer-Galley, 2007, p. 11). To determine coding reliability, a random sample of 150 turns was independently coded by the three coders. Krippendorff's $\alpha$ was .78 (95\% CI $[.71 ; .85])$ for the opinion category and .76 (95\% CI $[.68 ; .84])$ for the statement category. A variable "argument-based opinion" was computed and assigned to one if the turn included an opinion and an elaboration. The codes were aggregated up to the individual level. On average, the conversation partners stated about eight argument-based opinions $(M=8.26, S D=3.99)$.

Opinion effects. Opinion effects were measured by two items assessing respondents' perceptions on the five-point rating scale: (1) "I feel confirmed in my opinion through the conversation”, (2) “The conversation made me more determined in my views.” Both items were recorded so that higher values represent opinion effects in terms of opinion conversion. As the measurement is thought to reflect effects on partner's opinion, the partner's assessment served as variable in the analysis. The items showed internal consistency (Spearman-Brown $\rho$ $=.81)$ and were combined in an average index $(M=2.02, S D=.91)$.

Other-perceived opinion leadership. In the survey after the conversation, three items borrowed from the Childers (1986) scale were used to measure perception regarding opinion leadership in the political conversation. On five-point Likert scales, both dyadic partners made relative assessments on opinion leadership, that is, assessments if the opinion leadership items rather fit him-/herself or the conversation partner. Again, the partner's assessment, that is, the other-perceptions on opinion leadership in the political conversation, was used in the analysis. With a Cronbach's $\alpha$ of .70 the items can still be regarded as internally reliable (Nunnally, 1978). 


\section{Table 2}

Other-Perceived Opinion Leadership

In the previous political conversation, ...

(1) 1 = you gave a greater deal of $5=$ your conversation partner gave information.

a greater deal of information.*

(2) 1 = you told your conversation 5 = your conversation partner told you.* partner.

(3) 1 = your conversation partner $5=$ you were oriented towards the was oriented towards your opinion. opinion of your conversation partner.

Note. $n=154$, listwise deletion of cases; *the first two items were formulated in the reverse direction in the questionnaire, they were recorded for the analysis such that a higher value indicates that the partner is recognized as a situational opinion leader.

\section{Analysis}

To address Merton's (1968) notion that influence is a process implicating (at least) two people (p. 464), both conversation partners were considered in the analysis. In accordance with the actor-partner interdependence model (Kenny, Kashy, \& Cook, 2006), the actor's and the partner's self-perceived opinion leadership were integrated into the analyses on the correspondences between self-perceived opinion leadership and the aspects of the influence process (i.e., influence goal, influential communication, opinion effects; $R Q 1$ ) as well as between self- and other-perceptions $(R Q 2)$. To take account of the non-independence of dyadic data and to avoid biased significance tests, multilevel analyses were performed (Kenny 
et al., 2006). Snijders and Bosker's (1999) pseudo $R^{2}$ s were calculated to obtain effect sizes.

The analyses were run with HLM 7.0.

\section{Results}

Table 3 presents the results on $R Q 1$ about the correlations between self-perceived opinion leadership and the aspects of the influence process in political conversations.

\section{Table 3}

Opinion Leadership and its Correspondences with Aspects of the Influence Process

\section{Influential}

$\begin{array}{ccc}\text { Influence Goal } & \begin{array}{c}\text { Communication } \\ \text { (Argument-based }\end{array} & \begin{array}{c}\text { Opinion Effect } \\ \text { (Actor) }\end{array} \\ & \text { Opinion Giving; } & \text { (Partner) }\end{array}$

Actor)

\begin{tabular}{|c|c|c|c|c|c|c|c|c|c|}
\hline & \multicolumn{9}{|c|}{ Actor) } \\
\hline & $b$ & $S E$ & $p$ & $b$ & $S E$ & $p$ & $b$ & $S E$ & $p$ \\
\hline $\begin{array}{l}\text { Opinion Leadership } \\
\text { (Actor) }\end{array}$ & .265 & .09 & .004 & .774 & .32 & .018 & .217 & .08 & .008 \\
\hline $\begin{array}{l}\text { Opinion Leadership } \\
\text { (Partner) }\end{array}$ & -.135 & .09 & .133 & -.762 & .33 & .025 & -.152 & .07 & .034 \\
\hline & & & & & $=.($ & & & $=$. & \\
\hline
\end{tabular}

Note. $N=156, * n=154$ (listwise deletion of cases); robust standard errors were used to test statistical significance; all predictors have been centered at the grand mean; ${ }^{1}$ pseudo $R^{2}$ suggested by Snijders and Bosker (1999). 
It reveals that actor's opinion leadership corresponds with the goal to influence the partner's opinion. Additionally, opinion leadership is positively associated with argumentbased opinion giving. The higher the opinion leadership, the more argument-based opinions are contributed to the conversation. Interestingly, the partner's opinion leadership also affects the actor's communication behavior. With increasing partner's opinion leadership, the actor's amount of argument-based opinions decreases. With regard to opinion effects, the results show that the higher the self-perceived opinion leadership, the more the partner perceive a conversion of his/her opinion. Again, also the partner's opinion leadership plays a significant role: The more he or she perceived him- or herself as an opinion leader, the weaker the opinion change. In general, the actor's and partner's self-perceived opinion leadership explain five to seven percent of the variance of the different influence process aspects.

The results on $R Q 2$ - whether self-perceived opinion leadership corresponds with other-perceptions - demonstrate that the more the actor perceives him- or herself as an opinion leader, the more he or she is also designated as an opinion leader in the conversation by the partner $(b=.200, S E=.06, p<.001)^{6}$. However, again, the social recognition as opinion leader also depends on the partner's opinion leadership: With increasing selfperceived opinion leadership of the partner, the recognition of the actor as an opinion leader declines $(b=-.159, S E=.06, p=.011)$. The model explains approximately eleven percent of other-perceived opinion leadership $\left(R^{2}=10.52\right)^{7}$.

\footnotetext{
${ }^{6} n=154$ (listwise deletion of cases).

${ }^{7}$ Pseudo $R^{2}$ suggested by Snijders and Bosker (1999).
} 


\section{Discussion}

\section{Do Self-Perceived Opinion Leaders Actually Influence Others?}

The aim of the present research report was to shed light on the question of whether opinion leaders identified through self-designating scales actually lead opinions and, thus, influence others in political conversations. The study's findings show that self-perceived opinion leadership is attended by aspects of the influence process in political conversations, that is, the goal to influence opinions, influential communication, and opinion effects. Moreover, the results show that self-perceived opinion leadership correlates with otherperceived opinion leadership, indicating that it is socially recognized in political conversations. However, there are two findings that narrow the conclusion that selfdesignating opinion leadership scales are a valid way to identify opinion leaders, when it comes to the question of actual influence.

First, the results confirm Merton's (1986) notion that influence is a two-sided process. In nearly all models, both the actor's and the partner's opinion leadership play a significant role. In other words, the question of whether the general tendency to act as an opinion leader is realized in a situation also depends on the partner's opinion leadership. Because selfdesignating opinion leadership scales are unable to account for interaction partners and situations, they are not able to represent the complexity of social interactions entirely. Second, the effects found in this study are rather small, ranging from five to eleven percent of explained variance. Therefore, the present contribution concludes that opinion leadership scales may indicate what takes place in everyday political life — but only to a limited and complexity-reducing extent, which has to be kept in mind when it comes to the use of selfdesignating opinion leadership scales in communication research. 


\section{Limitations and Further Inquiries}

Although some procedures were used to heighten the study's validity—for example, the lab setting resembled a living room and familiar conversation partners were recruited-, the examined conversations may diverge from naturally occurring, non-observed conversations. This is particularly true with regard to the standardization of the conversation topic that was set to immigration policy. Thus, participants were not free to choose their topic of expertise, which might have limited the realization of opinion leadership in the current conversations. However, a correlation analysis shows that self-perceived opinion leadership is associated with self-perceived expertise on immigration policy $(r=.429, p=<.001)^{8}$, indicating that immigration policy is an adequate topic to study political opinion leadership.

Second, a modified version of Childers' (1986) scale was applied in which agree/disagree scales were used instead of the item-specific response options of the original scale. In a pre-study based on a sample of $N=118$ students (age: $M=22.15, S D=2.82 ; 68 \%$ female $)^{9}$, a comparison of both versions of the Childers scale did not reveal differences regarding the scales' reliability (item-specific response format: Cronbach's $\alpha=.89$; agree/disagree response format: Cronbach's $\alpha=.91$ ). However, there is empirical evidence indicating that, in general, agree/disagree scales have lower quality—in terms of reliability and validity — compared to specific response scales (Saris, Revilla, Krosnick, \& Shaeffer, 2010). Given this limitation, the present study does not claim to be a validation study of the Childers scale, but can be understood as a study on the validity of self-designating opinion leadership scales in general.

${ }^{8}$ Measured by the item "Generally, I feel well informed about the issue of immigration policy."

${ }^{9}$ A subsample of the students $(n=48)$ assessed items with the original item-specific response options, and another subsample $(n=70)$ indicated agreement with the items of the Childers scale on the agree/disagree format. 
The present study focused on the definitional core aspects of political opinion leadership, that is, the goal to influence, influential communication, and opinion effects. Of course, all three dimensions let space for further inquiries. For example, there might be more goals leading opinion leaders in political conversations, such as relational goals (Eveland, Morey, \& Hutchens, 2011). However, with its current focus, the study is able to provide first and important answers to the question as to whether self-perceived opinion leaders actually influence others.

\section{Conclusion}

This research report shows that self-designated opinion leadership is associated with influencing interactional partners and is socially recognized by others in political conversations, indicating that self-designating scales can be evaluated as a valid measurement. However, given the rather small effects and the significant role of the partner's opinion leadership, the report concludes that self-designating scales are able to capture the social reality's complexity only to a limited extent. 


\section{References}

Baumeister, R. F., Vohs, K. D., \& Funder, D. C. (2007). Psychology as the science of selfreports and finger movements: Whatever happened to actual behavior? Perspectives on Psychological Science, 2, 396-403. https://doi.org/10.1111/j.1745-6916.2007.00051.x

Eisinga, R., Grotenhuis, M., \& Pelzer, B. (2013). The reliability of a two-item scale: Pearson, Cronbach, or Spearman-Brown? International Journal of Public Health, 58, 637-642. https://doi.org/10.1007/s00038-012-0416-3

Eveland, W. P., Morey, A. C., \& Hutchens, M. J. (2011). Beyond deliberation: New directions for the study of informal political conversation from a communication perspective. Journal of Communication, 61, 1082-1103. https://doi.org/10.1111/j.14602466.2011.01598.x

Flynn, L. R., Goldsmith, R. E., \& Eastman, J. K. (1994). The King and Summers opinion leadership scale: Revision and refinement. Journal of Business Research, 31, 55-64. https://doi.org/10.1016/0148-2963(94)90046-9

Flynn, L. R., Goldsmith, R. E., \& Eastman, J. K. (1996). Opinion leaders and opinion seekers: Two new measurement scales. Journal of the Academy of Marketing Science, 24, 137-147.

Gnambs, T., \& Batinic, B. (2011). Convergent and discriminant validity of opinion leadership. Journal of Individual Differences, 32, 94-102. https://doi.org/10.1027/16140001/a000040

Gnambs, T., \& Batinic, B. (2012). The roots of interpersonal influence: A mediated moderation model for knowledge and traits as predictors of opinion leadership. Applied Psychology, 62, 597-618. https://doi.org/10.1111/j.1464-0597.2012.00497.x

Hellevik, O., \& Bjørklund, T. (1991). Opinion leadership and political extremism. International Journal of Public Opinion Research, 3, 157-181. https://doi.org/10.1093/ijpor/3.2.157 
Katz, E., \& Fialkoff, Y. (2017). Six concepts in search of retirement. Annals of the International Communication Association, 41, 86-91. https://doi.org/10.1080/23808985.2017.1291280

Katz, E., \& Lazarsfeld, P. F. (1955). Personal influence: The part played by people in the flow of mass communications. New York, NY: Free Press.

Kenny, D. A., Kashy, D. A., \& Cook, W. L. (2006). Dyadic data analysis. Methodology in the Social Sciences. New York: Guilford Press.

Kenny, D. A., \& La Voie, L. (1984). The social relations model. In L. Berkowitz (Ed.), Advances in experimental social psychology (pp. 141-182). Orlando, London: Academic Press. https://doi.org/10.1016/S0065-2601(08)60144-6

Lazarsfeld, P. F., Berelson, B., \& Gaudet, H. (1944). The people's choice: How the voter makes up his mind in a presidential campaign. New York, NY: Duell, Sloan and Pearce.

Mangold, F., \& Bachl, M. (2018). New news media, new opinion leaders? How political opinion leaders navigate the modern high-choice media environment. Journal of Communication, 68, 896-919. https://doi.org/10.1093/joc/jqy033

McCroskey, J., \& McCroskey, L. (1988). Self-report as an approach to measuring communication competence. Communication Research Reports, 5, 108-113. https://doi.org/10.1080/08824098809359810

Nunnally, J. C. (1978). Psychometric theory (2d ed.). McGraw-Hill series in psychology. New York: McGraw-Hill.

O’Keefe, D. J. (1997). Standpoint explicitness and persuasive effect: A meta-analytic review of the effects of varying conclusion articulation in persuasive messages. Argumentation and Advocacy, 34, 1-12. 
O’Keefe, D. J. (1998). Justification explicitness and persuasive effect: A meta-analytic review of the effects of varying support articulation in persuasive messages. Argumentation and Advocacy, 35, 61-75.

. Rice, R. E., Wu, Z., Li, L., Detels, R., \& Rotheram-Borus, M. J. (2012). Reducing STD/HIV stigmatizing attitudes through community popular opinion leaders in Chinese markets Human Communication Research, 38, 379-405. https://doi.org/10.1111/j.14682958.2012.01436.x

Rogers, E. M. (1995). Diffusion of innovations (4 ${ }^{\text {th }}$ ed.). New York, NY: Free Press.

Rogers, E. M., \& Cartano, D. G. (1962). Methods of measuring opinion leadership. Public Opinion Quarterly, 26, 435-441.

Saris, W., Revilla, M., Krosnick, J. A., \& Shaeffer, E. M. (2010). Comparing questions with agree/disagree response options to questions with item-specific response options. Survey Research Methods, 4, 61-79. https://doi.org/10.18148/srm/2010.v4i1.2682

Snijders, T. A. B., \& Bosker, R. J. (1999). Multilevel analysis: An introduction to basic and advanced multilevel modeling. London: Sage.

Solomon, S. (1978). Measuring dispositional and situational attributions. Personality and Social Psychology Bulletin, 4, 589-594. https://doi.org/10.1177/014616727800400419

Steyer, R., Schmitt, M., \& Eid, M. (1999). Latent state-trait theory and research in personality and individual differences. European Journal of Personality, 13, 389-408. https://doi.org/10.1002/(SICI)1099-0984(199909/10)13:5<389::AID-PER361>3.0.CO;2-A

Stromer-Galley, J. (2007). Measuring deliberation's content: A coding scheme. Journal of Public Deliberation, 3. Retrieved from http://www.publicdeliberation.net/jpd/vol3/iss1/art12

Summers, J. O. (1970). The identity of women's clothing fashion opinion leaders. Journal of Marketing Research, 7, 178-185. 
Troldahl, V. C., \& van Dam, R. (1965). Face-to-face communication about major topics in the news. Public Opinion Quarterly, 29, 626-634. https://doi.org/10.1086/267365

Valente, T. W., \& Pumpuang, P. (2006). Identifying opinion leaders to promote behavior change. Health Education \& Behavior, 34, 881-896.

https://doi.org/10.1177/1090198106297855

Weimann, G. (1994). The influentials: People who influence people. Albany, NY: State University of New York Press.

Zuroff, D. C. (1982). Person, situation, and person-by-situation interaction components in person perception. Journal of Personality, 50, 1-14. https://doi.org/10.1111/j.14676494.1982.tb00741.x 